Boise State University

ScholarWorks

Political Science Faculty Publications and

Presentations

Political Science Program

3-2021

\title{
Expanding Constituency Support Through Shared Local Roots in U.S. House Primaries
}

Charles Hunt

Boise State University

This article is protected by copyright and reuse is restricted to non-commercial and no derivative uses. Users may also download and save a local copy for the user's personal reference.

Hunt, C. "Expanding Constituency Support Through Shared Local Roots in U.S. House Primaries", American Politics Research, 49(2), pp. 233-244. Copyright (c 2020, The Author(s). Reprinted by permission of SAGE Publications.

https://doi.org/10.1177/1532673X20959606 


\title{
Expanding Constituency Support Through Shared Local Roots
}

\author{
in U.S. House Primaries
}

\begin{abstract}
This paper addresses the enduring connection of localism and place-based roots shared between many elected leaders and their constituents, which previous work has either ignored or improperly specified. I argue that representatives of the U.S. House with these roots - meaning authentic, lived experience in their districts prior to their officeholding - sustain more supportive constituencies in primary election stage. Using an original 7-point index of local biographical characteristics of incumbents seeking renomination from 2002-2018, I find that deeply-rooted incumbents are less than half as likely to receive a primary challenge, and on average perform more than 5 percentage points better in their primary elections when they are challenged. These gains take place even after taking district partisanship, national political conditions, incumbent ideology, and other primary factors into account, and should induce scholars to reconsider the importance of local representation even amidst a nationalizing political culture.
\end{abstract}

Keywords: Congress; congressional elections; primary elections; political geography; congressional candidates; representation 
This is an author-produced, peer-reviewed version of this article. The final, definitive version of this document can be found online at American Politics Research, published by SAGE. Copyright restrictions may apply. https://doi.org/10.1177/1532673X20959606. The content of this document may vary from the final published version.

Recent academic studies as well as popular media accounts of congressional elections have focused largely on how closely the reelection chances of a member of Congress (MC) are tied to the fortunes of their party at both the district and national levels. There is little doubt that partisanship of both MC and voter plays a crucial role in shaping congressional elections and representation (Jacobson 2015). However, there remains significant variation in MCs' relationships with their constituents that cannot be explained solely by partisanship. This variation has extensive impacts on electoral outcomes, particularly in primary elections, when party labels are unavailable as a cue to co-partisan voters. This paper leverages the primary election condition to identify the power of an attribute of incumbent MCs other than partisanship: the extent of their local biographical roots in their district.

Previous scholarship tells us that voters put a premium on incumbent-specific attributes such as race, religion, geography, and gender when deciding whether to reelect their representative (Gay 2001, Fenno 2003, Green and Guth 1991, Plutzer and Zipp 1996, Childs and Cowley 2011). Nonpartisan and nonideological connections establish stronger relationships between constituents and MCs, and thereby increase an MC's chances of renomination and reelection. An MC's local, place-based roots in the district is one such important but understudied connection between MCs and constituents. These roots provide both practical and symbolic representational benefits that help MCs connect with their constituents through placebased identity, values, and experiences unique to the district, as well as offering social, political, and financial benefits that improve MCs' electoral standing. Even in an era of nationalized political upheaval characterized by partisan and ideological polarization, local roots capture a shared sense of place-based identity that positively conditions how MCs relate to their constituents, and as a result improves their electoral performance. 
There is variation in the extent to which MCs possess this powerful shared local identity with their constituents. I capture these local roots using an original seven-point scale of verified biographical information that pinpoints MCs' authentic, lived experience within the geographic boundaries of their districts at different points in their pre-Congress lives. I use these indicators for incumbent House members from 2002-2018 to address the multiple ways in which shared local roots strengthen their foundational relationship with their constituents -- and by extension, their reelection chances -- at the first crucial stage of the reelection process: the party primary.

I specifically argue that local roots offer MCs a unique advantage in this context by expanding their support among same-party voters who support them above other co-partisan candidates in the primary election. Deep local roots in the district increase the proportion of an MC's co-partisan electorate who is personally committed to them in ways that go beyond the party label. I argue that potential primary challengers recognize this connection, and are in many cases deterred from challenging deeply-rooted incumbents; and that even when these incumbents do face a primary challenge, they achieve higher victory margins than incumbents without local roots. The empirical results support these conclusions: MCs with deep local roots are less than half as likely to attract a primary challenger than MCs without such roots. Among MCs who do receive a primary challenge, the deeply-rooted gain considerably more support among the primary electorate - more than 5 additional percentage points on their victory margins on average -- than those without roots. These analyses demonstrate that for MCs seeking reelection, local roots provide a highly desirable connection with their voters at the primary election stage.

This paper fills three crucial gaps in our understanding about local representation. First, while some prior scholarship has identified local identity as an important connection with constituents, none have clearly specified exactly how it impacts electoral outcomes. Here I 
identify the specific practical and symbolic benefits enjoyed by MCs with local roots in their districts, and the mechanisms by which these benefits help them retain electoral support. Second, previous work has used incomplete measures to capture the effects of place-based connections on electoral dynamics, relying primarily on the proximity of voters to a candidate's current residence or place of birth. None have explored these effects in the U.S. Congress. The seven original indicators of local roots I utilize here capture crucial untapped dimensions of the local backgrounds of over 3,000 incumbent-year observations in the House of Representatives from 2002 to 2018. Lastly, this paper situates local representational connections in the modern electoral context, in which congressional elections are thought to be dictated largely by nationalized forces like partisanship and ideology, and provides strong evidence that local roots matter to constituents even in our heavily polarized political moment.

\section{What Local Roots Are, and Why They Matter}

I define Local Roots as the extent of an MC's authentic lived experience within the local boundaries of their district as denoted by biographical markers such as whether an $\mathrm{MC}$ was born, went to school, or owned a business within the geographic boundaries of their district prior to their time in Congress (I will expand on these measures and their operationalizations below). I argue that these local roots constitute a place-based connection with the district that matters symbolically to constituents, facilitates practical grassroots advantages on the campaign trail, and results in more favorable electoral outcomes for incumbents with these roots.

The importance of a local connection between representatives and voters draws on earlier work by V.O. Key on the "friends and neighbors effect" (1949), which highlights the importance of statewide candidate localness in terms of their current geographic proximity to constituents. 
This phenomenon is essentially the advantage candidates enjoy in the town, county, state, or other geographic area in which they currently reside, compared to other areas in their electoral jurisdiction. Key and others have found support for the friends-and-neighbors voting effect at different levels of government (Tatalovich 1975, Lewis-Beck and Rice 1983, Johnston et al. 2016), though notably not in the U.S. Congress. These studies demonstrate that constituents recognize local candidates and value them electorally (Rice and Macht 1987, Bowler et al. 1993, Shugart and Valdini 2005, Johnson and Rosenblatt 2006, Jacobs and Munis 2018, Stevens et al. 2018). Parties in the comparative context have also been shown to actively seek out candidates with local ties (Gallagher 1980, Parker 1982, 1986, Weeks 2008).

Political actors in many electoral contexts clearly identify localism as an electorally valuable connection between voters and representatives, but what gives this connection its value? First, I argue that local roots offer an MC tangible, practical benefits in building a deep and lasting coalition of voter support in the district. an $\mathrm{MC}$ with an extensive personal history in the district will have a more expansive baseline of social, economic, and political networks in the district that predate their initial election and aid their fundraising, outreach and overall campaign efforts throughout their career. Thus, deep roots give MCs a head start in terms of building political infrastructure in the district, establishing a positive local reputation, and broadening their base of support. Although this is similar in some ways to more general name recognition (Street 2004, McDonald and Samples 2007, Herrnson 2015), local roots offer a deeper and ultimately more advantageous brand of name recognition because it is specific to that electoral jurisdiction. Indeed, previous work has theorized that place-specific name recognition and local political connections underlie the "friends-and-neighbors" effect (Bowler et al. 1993, Gimpel et al. 2008, Johnston et al. 2016). 
Local roots also provide MCs with symbolic benefits that imbue voters with a sense of trust that is difficult to replicate. A number of recent works have explored the concept of "place" as a psychologically crucial category of social identity that belongs in the discussion with other important identities like race, gender, and of course party. In particular, these works demonstrate that local ties and interests are important framers of political attitudes (Cutler 2007) and that Americans are highly protective of their local identities - and even resentful towards candidates who don't share them (Cramer 2016, Jacobs and Munis 2018). But when politicians do share this local identity with the community they represent, it cuts across partisanship and has been shown to strengthen MCs' personal representational connections with their constituents (Cain et al. 1987, Parker and Parker 1993, Herrera and Yawn 1999).

More specifically, MCs with deep biographical roots in their jurisdictions are equipped with an authentic understanding of the issues that affect their local communities because they have lived in the district or have political experience dealing with these issues in the local context. These MCs are better able to represent the district because they have been a voter in the district themselves. Constituents value this type of understanding, identity, and personal experience; they see the MC as "one of them" and reward this status with their trust, and more instrumentally, their vote (Fenno 1978, Bianco 1994). A deeply-rooted MC is therefore uniquely qualified to represent their particular district rather than generically qualified to hold any political office. Because local roots can be deepened only in a particular geographic space, they are a valuable symbolic connection that gives MCs a comparative advantage over potential primary competitors without such roots. 


\section{Expanding Constituency Support in the Primary}

While these practical and symbolic benefits have theoretical importance to voters of all partisan persuasions, I argue that they are particularly impactful for an MC's relationship to their primary constituency. It is important to understand how local roots impact the primary context for a number of reasons. Even though incumbents win renomination a vast majority of the time, every electoral cycle features at least one losing incumbent, and this past decade has seen a number of losses from high-profile MCs like Joe Crowley (D-NY) and Eric Cantor (R-VA). And because of the uniqueness of the primary electorate, as well as the exorbitant amount of money spent on many primary races, it is crucial to understand which dynamics are most influential on incumbents' success of failure at this stage even if most ultimately prevail.

One notable characteristic of primary voters is that MCs already relate to them on a partisan dimension, and therefore are also in greater alignment with them on the issues than with other voters. As a result, partisanship is not a differentiating factor between candidates and voters in the primary election stage. And while primaries are often fought in the ideological space, prior work has shown that the actual ideological differences between the candidates are usually slight (Poole and Daniels 1985, Brady et al. 2007). When candidates are not sharply distinguishable on traditional dimensions like party and ideology, it makes other distinctions between the candidates more meaningful and relevant than they otherwise might be (Banks and Kiewiet 1989). For instance, one frequently noted difference between primary candidates is incumbency, which scholars have found provides an electoral boost to MCs, particularly in the primary (Gelman and King 1990, Ansolabehere et al. 2007, Carson et al. 2007). Notably, the analyses here focus on variation only among incumbent members of Congress rather than other candidates ${ }^{1}$, and so this difference is muted. Still, the logic of candidates wanting to distinguish themselves from 
potential primary opponents who share their partisan and ideological leanings applies and makes having local roots an effective electoral advantage. ${ }^{2}$

Beyond these mechanisms, local roots in the district add distinction to an MC's standing with primary voters in both symbolic and practical ways. First, local roots offer MCs an additional dimension on which they can relate personally to their primary voters. They instill in an MC's co-partisan constituents a sense of loyalty to that $\mathrm{MC}$ in particular, rather than just any generic co-partisan candidate. When a voter can identify with a member who, for example, grew up in the same town as they did or went to their high school, the connection between them is multi-layered, and transcends the partisan connection they likely already share. In short, when party loyalty is less as a distinguishing characteristic between candidates, personal loyalty fills the void and plays a larger role. This loyalty manifests electorally for co-partisan voters via two mechanisms: first, local ties in the district should make same-party voters less likely to "roll off" and only vote for top-of-the-ballot candidates for Senate or President because of the stand-out nature of the locally-grown MC (Meredith 2013). Second, local roots should induce lowerpropensity same-party voters, who may typically vote only in presidential races or not at all, to turn out in the primary, thus increasing MCs' electoral margins. Primary voters are therefore less likely to waver in their support for a locally-rooted representative in a primary election.

Local roots in the district also have the effect of making these MCs less expendable as a representative. The knowledge, familiarity, and ultimately the loyalty deeply-rooted MCs enjoy is deeply valuable to the constituent relationship (Fenno 1978, 2000, Feld and Grofman 1991, Bianco 1994, Gay 2002). Moreover, when this loyalty is cultivated as a result of pre-established local roots in the district, it cannot by definition be easily manufactured or replaced because it is homegrown. While other co-partisan candidates could move to the district with impressive 
ideological, educational, or professional credentials (and many do), these do not qualify a candidate to represent that particular district in the way that local roots do. Because local roots are a hard-won commodity, co-partisan constituents who already support a deeply-rooted MC will value them even more, and perceive them as far less replaceable, even with another candidate with the same party affiliation and ideological leanings.

There are also several practical ways in which local roots have this effect in the primary. As noted above, local roots expand an MC's political infrastructure in the district, as well as personal and professional networks. Specifically, an MC's pre-established relationships with local activists, business interests, social clubs, and professional organizations in the district are invaluable in terms of organizing not (just) around a party, but rather that particular MC. A deeply-rooted MC enjoys sustained local legitimacy by having the opportunity for long-standing associations with these local groups. And because these networks predate an MC's time in Congress, they help MCs develop and maintain a core of personally-dedicated supporters who have been with them "from the beginning." These voters will therefore fight against any effort to replace them, or at the very least be less likely to abandon them for another otherwise-similar candidate. Deep roots also strengthen MCs' political infrastructure

Deeply-rooted MCs are also better-able to establish long-standing personal ties with local and state party organizations, having begun their political careers in their midst, and often with their help. These long-held local ties may make formal and informal local party organizations more likely to fight for an incumbent, as well as deter potential challengers for the nomination by denying them resources and networks that the incumbent locked down long ago (Hassell 2016). Although recent scholarship finds a smaller role for state and local party institutions in American politics (Hershey 2017, Carson and Roberts 2013), MCs can still attract the attention, assistance, 
and (perhaps most importantly) the resources of party elders and elected officials in the district if they have long been present and active in their district. Experienced professional staff of former elected members of the party, for example, may be more likely to advise or join the campaigns of locally-established MCs. High naturally-occurring overlap between these personal and professional networks help locally-rooted MCs monopolize local political networks such that potential challengers, however otherwise qualified, are deterred from trying to break through.

I argue that these many important mechanisms amount to a significant expansion of an MC's most ardent co-partisan constituency. This core of reliable support makes it far less likely that potential co-partisan opponents will emerge in the primary. As a result, I propose the following:

Hypothesis 1: The deeper an incumbent $M C$ 's local roots in their district, the less likely they are to attract a challenger in the primary.

However, the entry of opponents into the primary is ultimately a phenomenon out of the control of the incumbent. For many of the aforementioned reasons, I also expect that even when MCs do receive one or more challengers in their primary election, they will repel them with greater ease. It is true that incumbents rarely fail to be renominated by the party's voters in the district. But given the well-established link between competitiveness and fundraising necessity (McAdams and Johannes 1987, Jacobson 1990, Gerber 1998), winning their primaries by as great a margin as possible is a deeply desirable and substantively important outcome for incumbents, who must immediately begin spending money and time to win in the general election. For these and other reasons, it is important to estimate the extent to which local roots can boost incumbent MCs who do attract primary opponents. Therefore: 
Hypothesis 2: The deeper an incumbent MC's local roots in their district, the higher their margins of victory will be in their primary elections.

\section{Defining Local Roots Empirically}

Traditionally, local connections have been defined empirically in narrow terms, with most studies relying on simple measures of residential proximity (Gimpel et al. 2008, Evans et al. 2017) or candidate birthplace (Shugart et al. 2005, Tavits 2010), both of which have significant limitations. Not only is current residential proximity possibly endogenous to current political considerations, but it also is often a placeholder address where members of Congress spend little time once elected. It also is not an accurate measure of historical "roots", since it only captures current residence. The birthplace measure is an important one that I utilize in this project, but captures only a snapshot in time of local roots. To more fully understand the effects of MCs' local roots on their representational connection with constituents, I use an original additive index of seven indicators that capture an MC's local connection at different points in their pre-Congress lifetime. All measures were coded by the author from the 107 th- 115 th Congresses using the Biographical Directory of the United States Congress, the U.S. Census Bureau, and Congressional Quarterly's Member Profiles. The measures are as follows:

\section{Family Political Roots in the District}

MCs who have a family member who previously represented the district in some capacity makes the current MC a trusted, "known quantity." Constituents have experience with and were, at least for a while, satisfied with the representation they received from that family member.

Additionally, the MC benefits from strong local family name recognition. Rep. John Duncan (RTN), who served Tennessee's 2nd District following his father, put these advantages plainly at a 
recent event: "Because my daddy and I held this office for 54 years, if my constituents know one

thing, it's the name 'Duncan." ${ }^{33}$ Official congressional biographies indicate whether members of Congress were preceded in their districts by family members of previous generations, as well as whether family were previously state MCs, mayors, or other local officials. ${ }^{4}$

\section{Birth and Educational Attainment in the District}

As noted, candidate birthplace has been used in previous work to measure localness in state and local politics (Shugart and Valdini 2005, Tavits 2010, Meredith 2013), but rarely at the federal level. If an MC was born in their district, they likely grew up there, understand the area, and have sentimental attachments to their locality that deepen their connection to the place, and by extension to the voters who live there currently. I also capture whether an MC went to high school, undergraduate, or graduate school in the district. If an MC attended school in the district, they are likely to have lived, worked, or made personal and professional connections there during their pre-Congress life. Growing up or attending school in the district also gives MCs a sense of what their constituents are thinking and feeling because they have been a constituent in the district. In essence, these MCs are the people they are representing. Using multiple measures of district presence during young adulthood and early-career adulthood helps account for whether MCs may have moved into (or away from) the district at an earlier age. I code all four of these measures based on whether the city or town of an MC's birth or educational institution is either fully or partially located in their current district.

\section{Business Ownership in the District}

Members of Congress have traditionally held extensive business experience compared to the general public (Ornstein et al. 2009), and scholars have explored its influence on 
This is an author-produced, peer-reviewed version of this article. The final, definitive version of this document can be found online at American Politics Research, published by SAGE. Copyright restrictions may apply. https://doi.org/10.1177/1532673X20959606. The content of this document may vary from the final published version.

policymaking activity (Witko and Friedman 2008, Carnes 2013, Francis and Bramlett 2017) and candidate emergence (Lawless and Fox 2005). Unlike these studies, however, I focus on the place-based dimension of MCs' business experience and determine which members of Congress began or inherited a local family business. This status provides MCs with firsthand knowledge of the particular economic culture of their district, and the place-based challenges and rewards that come with it. This unique perspective helps them relate to and create connections with other business owners in the district, who can wield considerable political. Owning a business in the district also can provide valuable inroads to economic networks that can pay dividends in campaigns - specifically in the fundraising and spending realms.

\section{Local Political Experience}

In addition to name recognition, an MC's local political experience has an added advantage because it conveys understanding of their particular district's political and policy culture. They have valuable and authentic knowledge of local political power centers, thought leaders and opinion makers in the district, which contributes to the head start they have over less rooted counterparts. Additionally, local political experience comes with less partisan baggage than most state or federal offices because many local political posts are nonpartisan, and their issue profile is distinctly local rather than national. By serving in local office, MCs can credibly claim to know how to solve local issues, and to bring those solutions to Congress. This component of local roots is isolated only to previously-held local elected office. Undifferentiated political experience is an important type of generic qualification, but local political experience is specific training for the job a candidate is running for: representing that particular place. While in-district birth or school attendance gives an MC information about what it's like to be a voter in the district, local political experience is a preview of what it's like to represent that district. 


\section{The Local Roots Index}

These seven previously underutilized variables are used to create an additive original Local Roots Index that ranges from 0-7.5 These components serve as important landmarks of MCs' local roots in the district, and are a more complete picture of how much lived experience they have in the district. Using measures that span MCs' pre-Congress lifetime makes it possible to distinguish between an MC who, for example, moved away from the district as a child and only moved back in order to run for Congress - or alternatively, an MC who was technically born elsewhere but grew up and lived the entire remainder of their lives in their district. Surely the latter MC has more local knowledge, connections, and symbolic attachment to their district than the former. Capturing these distinctions is one primary advantage of using a composite index. ${ }^{6}$

Additionally, these new data are more reflective of the range of mechanisms by which local roots positively affect electoral dynamics in the district. For example, educational attainment in the district helps MCs create extensive social networks and early professional connections in the area; local political experience provides fluency and insight into issues of particular local importance; local business ownership provides economic networking opportunities crucial to the campaign process; local birthplace is a meaningful symbolic sign that an MC's roots are long-standing, and that they can therefore be trusted. The Local Roots Index ensures that there is no bias towards or against any one of these mechanisms, and that MCs get proper credit when they possess more than one of these background attributes. ${ }^{7}$ Figures 1 and 2 show the descriptive distribution of each of the seven component factors and of the additive Local Roots Index, respectively, for all incumbent House members from 2002-2018. 
The dependent variable for H1 was calculated using FEC election returns to create a binary indicator of whether an incumbent faced a primary opponent or not. To account for the presence of primary opponents with little campaign or who mount no serious challenge, I also classify as unopposed in the primary election all incumbents who received $95 \%$ or more of the primary vote. ${ }^{8}$ For $\mathrm{H} 2$ (primary victory margin), I used the same FEC election returns to create a continuous measure of primary margin of victory: the incumbent's share of the primary election vote minus the combined shares of all other candidates on the ballot. Initial descriptive analysis shows promise for the Local Roots Index as a conditioner of incumbents' primary election outcomes. Figures 3 and 4 shows the average percentage of incumbents who attract a challenger decreasing steadily as the Local Roots Index increases; and Figure 4 illustrates the opposite (expected) trend for incumbents' share of the primary vote when they do face a challenger.

[Insert Figures 3 and 4 about here]

\section{Other Data \& Methodology}

Despite these initial descriptive trends, a number of possible confounding factors must be held constant in the full primary election models (H1 and $\mathrm{H} 2)$ in order to establish controls and to compare the effects of local roots with other important factors in primary elections. First, I include an indicator of whether the state uses the "closed primary" system, which limits primary voting only to voters affiliated with that party and could affect incumbent fortunes. I also include an indicator of whether a state uses a nonpartisan blanket (or "jungle") primary, in which all candidates from both parties run in the same primary. ${ }^{9}$ In districts with these types of primaries, the likelihood of seeing an opponent in the primary increases. Since primaries are also often 
fought on ideological grounds (i.e. the incumbent not being "liberal" or "conservative" enough),

I also include a control for ideological extremism relative to the party median in the House based on first-dimension DW-NOMINATE scores. Other district-and MC-level controls were included for both models, including majority-minority representation, since previous literature shows that shared racial connection is a key component of representation (Gay 2001, Banducci et al. 2004). The partisan lean of a district is also included and is measured by an incumbent-adjusted version of the Cook Political Report's Partisan Voting Index, which uses the prior two presidential election results in the district and compares them to the national average. Since incumbents' reelection chances are tied to views of their party nationally, a measure for national partisan advantage - a pre-election polling average of the "generic congressional ballot" question - is included. I also include controls for whether an MC is a chamber or party leader, and how long they have served in Congress. ${ }^{10}$ Finally, to account for possible effects of generic rather than place-based versions of these qualifications, I control for whether the incumbent had any postgraduate degree; generic business experience; or prior elected experience regardless of location, all to ensure that these local component of the Local Roots Index are capturing only the place-based dimension of this qualification.

To specify all three models, I use mixed-effects modeling with random intercepts by MC. Applying random intercepts captures the theoretical assertions made earlier: that local roots established before an MC's time in Congress do not vary over their career (and therefore cannot be feasibly modeled using fixed effects), but rather offer a "head start" in building up and deepening their relationship with constituents that varies by MC and transcends partisanship. Using random intercepts acknowledges and rectifies the fact that incumbents running for reelection in multiple years between 2002-2018 are not fully independent observations. In doing 
so, this also helps account for unobservable differences between MCs that could possibly affect electoral outcomes beyond the factors already controlled for. The units of observation are incumbent MCs seeking renomination from 2002-2018.

\section{Results}

Hypotheses 1 and 2 proposed that incumbents with deep local roots would both help them ward off primary challengers and increase their margins against any challengers that do emerge. These expectations are borne out in the results, depicted in Tables 1 and 2: local roots have a clear negative effect on the likelihood an incumbent attracts a primary challenger, and a clear positive effect on their primary election margins when they do attract a challenger. The effect of local roots is highly statistically significant, even after controlling for factors like partisanship, tenure length, racial alignment, and ideological extremism in their legislative activity, which are commonly acknowledged influencers of incumbents' electoral standing in the primary stage. Additionally, the effects of these conventional variables point in the expected directions: for example, closed primaries limit the range of constituents who can vote in primaries, thus dampening the demand for a wider range of candidates; and the jungle primary condition significantly increases an incumbent's probability of attracting a challenger, and lowers their margins when they do.

[Insert Tables 1 and 2 about here]

To examine the substantive impacts of these effects, I first generate predicted probabilities of primary opposition based on all observed values of the Local Roots Index, which 
are depicted in Figure 5. The results of this exercise are perhaps the most striking yet: deep local roots reduce the likelihood of facing primary opposition by more than half. Holding all other factors constant, MCs without any local roots are predicted to attract a primary challenger about $43 \%$ of the time, while those with the deepest roots do so about $20 \%$ of the time. This means that the most "carpetbagging" MCs without local roots face legitimate primary challengers more than twice as often as their deeply-rooted counterparts.

[Insert Figure 5 about here]

This is a tremendously consequential result for a variety of reasons. Even if incumbents are rarely ousted in the primary, a serious challenge drains crucial campaign resources that could otherwise be used in the general election, as well as the time and energy an MC must spend campaigning. Facing a primary challenger also provides co-partisan constituents with an alternative to an incumbent $\mathrm{MC}$, and sows doubt among those whom the MC should theoretically have strong support, and can dampen general election turnout.

Even when MCs are unable to stave off a challenger ${ }^{11}$, local roots continue to offer an invaluable connection to their co-partisan constituents, which results in improved electoral performance. Local roots have highly statistically significant and positive effects in primary elections. Figure 6 displays the predicted primary election margins of victory based on all values of the Local Roots Index. This distribution of effects indicates a roughly 11-point predicted difference in primary election victory margins between incumbents with the lowest and highest levels of local roots in their districts, with smaller but still meaningful differences between incumbents closer to the median. 


\section{[Insert Figure 6 about here]}

Notably, the number of terms an MC has served in Congress appears to have null and directionally negative effects on their primary election margins. This is a particularly significant finding given the attention that has been paid to the incumbency effect in the previous literature, and its potential as a distinguishing factor that primary voters use to positively differentiate incumbents from lesser-known challengers. Since this analysis compares incumbents running for reelection to each other, the "incumbency advantage" is not strictly a factor in the measurement of the dependent variable. Still, one might imagine that MCs who have served in their districts for many terms have established themselves as the candidate of choice for their party's voters, as well as fundraisers and local political leaders.

The substantive impact of local roots in contested primaries may be best assessed by again comparing them with the predicted average effects ${ }^{12}$ of the other independent variables in the model. Figure 7 shows not only that local roots compare favorably with other measures, but that they are significantly more impactful than every other factor except whether the state holds jungle or top-two primaries for congressional candidates (which was omitted from this figure due to its size). Most striking is the fact that local roots actually outpace ideological extremism in their effects on primary success. As expected, ideologically-extreme incumbents do appear to have a more supportive primary electorate, who themselves tend to have more extreme and cohesive policy views than the average general election voter. But this comparison implies that an incumbent's local, place-based connection with primary voters is at least as impactful than their ideological connection. 
[Insert Figure 7 about here]

\section{Conclusions}

Tests of the effects of local roots on primary election fortunes provide striking evidence that local ties significantly and positively impact an MC's standing with their co-partisan electorate. MCs with deep local roots are less than half as likely to attract a primary challenger than their less-rooted counterparts; and when these MCs are challenged in the primary, they win by margins almost 6 percentage points higher than comparable MCs with limited roots. These results should compel scholars of congressional elections to reconsider what factors shape electoral dynamics in the district in the primary election stages, especially factors that allow MCs to differentiate themselves from one another. Local roots offer an important distinguishing characteristic for incumbent MCs in primary contests where ideological and partisan differences between the candidates are small. They also establish deep and lasting political, economic, and social networks that help them deter potential rivals for their party's nomination in the district.

Overall, these results indicate that the depth of an MC's local roots among their constituency should be considered alongside other more traditional factors in models used to predict electoral outcomes in the district. Not only do local roots have substantial impacts at the primary election stage, but the magnitude and statistical confidence of these impacts rival or in many cases overtake those of other important determinants of electoral outcomes like partisanship, ideology, tenure length, and election laws. Importantly, local roots vary extensively between incumbent MCs, and help explain different electoral outcomes that occur between otherwise-similar incumbent-constituency pairings. 
One potential factor that could complicate the potency of these benefits is the type of geographic area that makes up a particular district. That is, do local roots have different impacts in urban, suburban, or rural districts? Are less geographically mobile districts more apt to appreciate local roots? Preliminary results that separate districts into these subsamples, depicted in Figures A2.1, A2.2 and A2.3 in the Appendix actually demonstrate that local roots have a significant impact regardless of a district's geographic mobility, urban/rural status, or population density. Future work might dig deeper on these differences to assess which types of districts of subconstituencies might be more receptive to local roots as a representational credential.

These findings also contribute a unique perspective to the emergent theoretical debate regarding the nationalization of partisan politics in the U.S. Influential studies like those of Hopkins (2018) offer compelling evidence that electoral politics are increasingly structured around national issues, partisan identities, and polarized ideologies. While comfortably situated in the modern era of American politics characterized by the most recent three presidencies, the sample of elections used in this study can also be leveraged to capture over-time changes. Splitting the sample between the two most recent decades show some expected changes: that the influence of ideological extremism increased in the current decade, while the influence of local roots declined somewhat. ${ }^{13}$ Even so, that such a distinctly nonpartisan and nonideological connection with constituents like local roots can matter during this time speaks volumes about its resilience in shaping the MC-constituent relationship, and about the gaps that remain in explaining electoral performance that nationalized partisanship does not yet satisfy. "All politics" is clearly no longer "local" as Speaker Tip O’Neill once mused; but nor is it all national.

Nationalization trends also undoubtedly make it increasingly difficult for reelectionseeking MCs to appeal to both ideologically extreme primary electorates and partisan-polarized 
This is an author-produced, peer-reviewed version of this article. The final, definitive version of this document can be found online at American Politics Research, published by SAGE. Copyright restrictions may apply. https://doi.org/10.1177/1532673X20959606. The content of this document may vary from the final published version.

general electorates; as a result, MCs often must sacrifice support with one subconstituency to please another (Key and Others 1966, Brady and Schwartz 1995, Schmidt et al. 1996, Gerber and Morton 1998, Michael Alvarez 1998). For example, when a Democrat appeals to an increasingly extreme base in their primary election by emphasizing progressive bonafides, they risk alienating more moderate and conservative constituencies in the general election.

Local roots pose no such risk, and as a result may also represent a potential avenue for scholars and other political practitioners searching for ways to de-polarize electorates on smaller scales. However highly-engaged, deeply partisan, and ideologically extreme primary voters may be, they live in and care about the district as a place, and as their home; so, too, do many general election voters who may not share an MC's ideological or even partisan identity. By its very definition, the local identity of the district is the one constituents of all stripes have in common. As Hopkins (2018) notes in his influential work on nationalization, "One doesn't have to espouse certain political views to be a proud Rhode Islander or South Dakotan.” (11) Shared, place-based roots therefore represent a rare commodity for reelection-seeking MCs in an age of partisan nationalization: a local connection with their district that has widespread appeal and a significant, positive impact on an MC's electoral fate regardless of party or ideology.

\section{References}

Banks, J. S., \& Kiewiet, D. R. (1989). Explaining Patterns of Candidate Competition in Congressional Elections. American Journal of Political Science, 33(4), 997-1015.

Bianco, W. T. (1994). Trust: Representatives and Constituents. University of Michigan Press.

Boatright, R.G. 2013. Getting Primaried: The changing politics of congressional primary challenges. University of Michigan Press.

Bowler, S., Donovan, T., \& Snipp, J. (1993). Local sources of information and voter choice in State elections: microlevel foundations of the" friends and neighbors" effect. American Politics Quarterly, 21(4), 473-489.

Brady, D., \& Schwartz, E. P. (1995). Ideology and interests in congressional voting: The politics of abortion in the US Senate. Public Choice, 84(1-2), 25-48. 
Brady, D. W., Han, H., \& Pope, J. C. (2007). Primary Elections and Candidate Ideology: Out of Step with the Primary Electorate? Legislative Studies Quarterly, 32(1), 79-105.

Cain, B., Ferejohn, J., \& Fiorina, M. (1987). The personal vote: Constituency service and electoral independence. Harvard University Press.

Carnes, N. (2013). White-Collar Government: The Hidden Role of Class in Economic Policy Making. University of Chicago Press.

Childs, S., \& Cowley, P. (2011). The Politics of Local Presence: Is there a Case for Descriptive Representation? Political Studies, 59(1), 1-19.

Cramer, K.J., 2016. The Politics of Resentment: Rural consciousness in Wisconsin and the rise of Scott Walker. University of Chicago Press.

Cutler, F., 2007. Context and attitude formation: Social interaction, default information, or local interests? Political Geography, 26(5), 575-600.

Evans, J., Arzheimer, K., Campbell, R., \& Cowley, P. (2017). Candidate localness and voter choice in the 2015 General Election in England. Political Geography, 59, 61-71.

Feld, S., \& Grofman, B. (1991). Incumbency Advantage, Voter Loyalty and the Benefit of the Doubt. Journal of Theoretical Politics, 3(2), 115-137.

Fenno, R. (1978). Home style: House members in their districts. Little, Brown.

Fenno, R. F. (2003). Going Home: Black Representatives and Their Constituents. University of Chicago Press.

Fenno, R. F., Jr. (2000). Congress at the Grassroots: Representational Change in the South, 19701998. Univ of North Carolina Press.

Francis, K., \& Bramlett, B. (2017). Precongressional Careers and Committees: The Impact of Congruence. American Politics Research, 45(5), 755-789.

Gallagher, M. (1980). Candidate Selection in Ireland: The Impact of Localism and the Electoral System. British Journal of Political Science, 10(4), 489-503.

Gay, C. (2001). The Effect of Black Congressional Representation on Political Participation. The American Political Science Review, 95(3), 589-602.

Gay, C. (2002). Spirals of Trust? The Effect of Descriptive Representation on the Relationship between Citizens and Their Government. American Journal of Political Science, 46(4), 717-732.

Gerber, A. (1998). Estimating the effect of campaign spending on senate election outcomes using instrumental variables. The American Political Science Review, 92(02), 401-411.

Gerber, E. R., \& Morton, R. B. (1998). Primary Election Systems and Representation. Journal of Law, Economics, \& Organization, 14(2), 304-324.

Gimpel, J. G., Karnes, K. A., McTague, J., \& Pearson-Merkowitz, S. (2008). Distance-decay in the political geography of friends-and-neighbors voting. Political Geography, 27(2), 231-252.

Green, J. C., \& Guth, J. L. (1991). Religion, Representatives, and Roll Calls. Legislative Studies Quarterly, 16(4), 571-584.

Hassell, H. J. G. (2016). Party Control of Party Primaries: Party Influence in Nominations for the US Senate. The Journal of Politics, 78(1), 75-87.

Herrera, R., \& Yawn, M. (1999). The Emergence of the Personal Vote. Journal of Politics, 61(1), $136-150$.

Hershey, M. R. (2017). Party politics in America. Routledge.

Hopkins, D.J., 2018. The increasingly United States: How and why American political behavior nationalized. University of Chicago Press. 
This is an author-produced, peer-reviewed version of this article. The final, definitive version of this document can be found online at American Politics Research, published by SAGE. Copyright restrictions may apply. https://doi.org/10.1177/1532673X20959606. The content of this document may vary from the final published version.

Jacobs, N. F., \& Munis, B. K. (2018). Place-Based Imagery and Voter Evaluations: Experimental Evidence on the Politics of Place. Political Research Quarterly. http://journals.sagepub.com/doi/abs/10.1177/1065912918781035

Jacobson, G. C. (1990). The Effects of Campaign Spending in House Elections: New Evidence for Old Arguments. American Journal of Political Science, 34(2), 334-362.

Jacobson, G. C. (2015). It's nothing personal: The decline of the incumbency advantage in US House elections. Journal of Politics, 77(3), 861-873.

Johnson, C., \& Rosenblatt, G. (2006). Do MPs have the "right stuff"? Parliamentary Affairs, 60(1), $164-169$.

Johnston, R., Wickham-Jones, M., Pattie, C., Cutts, D., \& Pemberton, H. (2016). Friends and neighbours voting revisited: The geography of support for candidates to lead the UK's Labour party. Political Geography, 55, 1-9.

Key, V. (1949). Southern politics in State and Nation. University of Tennessee Press.

Key, V. O., \& Others. (1966). The responsible electorate. Belknap Press of Harvard University Press. Lawless, J. L., \& Fox, R. L. (2005). It Takes a Candidate: Why Women Don't Run for Office. Cambridge University Press.

Lewis-Beck, M. S., \& Rice, T. W. (1983). Localism in Presidential Elections: The Home State Advantage. American Journal of Political Science, 27(3), 548-556.

McAdams, J. C., \& Johannes, J. R. (1987). Determinants of Spending by House Challengers, 197484. American Journal of Political Science, 31(3), 457-483.

Meredith, M. (2013). Heterogeneous friends-and-neighbors voting. University of Pennsylvania Mimeo. http://www.sas.upenn.edu/ marcmere/workingpapers/HeterogeneousLocalism.pdf

Michael Alvarez, R. (1998). Information and Elections. University of Michigan Press.

Ornstein, N. J., Mann, T. E., \& Malbin, M. J. (2009). Vital Statistics on Congress 2008. Brookings Institution Press.

Parker, A. J. (1982). The "friends and neighbours" voting effect in the Galway West constituency. Political Geography Quarterly, 1(3), 243-262.

Parker, A. J. (1986). Geography and the Irish Electoral System: The Presidential Address of 1984-85. Irish Geography: Bulletin of the Geographical Society of Ireland, 19(1), 1-14.

Parker, S. L., \& Parker, G. R. (1993). Why Do We Trust Our Congressman? Journal of Politics, 55(2), 442-453.

Plutzer, E., \& Zipp, J. F. (1996). Identity Politics, Partisanship, and Voting for Women Candidates. Public Opinion Quarterly, 60(1), 30-57.

Poole, K. T., \& Daniels, S. R. (1985). Ideology, Party, and Voting in the U.S. Congress, 1959-1980. The American Political Science Review, 79(2), 373-399.

Rice, T. W., \& Macht, A. A. (1987). Friends and Neighbors Voting in Statewide General Elections. American Journal of Political Science, 31(2), 448-452.

Schmidt, A. B., Kenny, L. W., \& Morton, R. B. (1996). Evidence on Electoral Accountability in the U.S. Senate: Are Unfaithful Agents Really Punished? Economic Inquiry, 34(3), 545-567.

Shugart, M. S., \& Valdini, M. E. (2005). Looking for locals: voter information demands and personal vote-earning attributes of legislators under proportional representation. American Journal of. http://onlinelibrary.wiley.com/doi/10.1111/j.0092-5853.2005.00133.x/full

Shugart, M. S., Valdini, M. E., \& Suominen, K. (2005). Looking for Locals: Voter Information Demands and Personal Vote-Earning Attributes of Legislators under Proportional Representation. American Journal of Political Science, 49(2), 437-449. 
Stevens, B. A., Islam, M. M., de Geus, R., Goldberg, J., McAndrews, J. R., Mierke-Zatwarnicki, A., Loewen, P. J., \& Rubenson, D. (2018). Local Candidate Effects in Canadian Elections. Canadian Journal of Political Science/Revue Canadienne de Science Politique, 1-14.

Tatalovich, R. (1975). “Friends and Neighbors” Voting: Mississippi, 1943-73. The Journal of Politics, 37(3), 807-814.

Tavits, M. (2010). Effect of Local Ties On Electoral Success and Parliamentary Behaviour: The Case of Estonia. Party Politics, 16(2), 215-235.

Weeks, L. (2008). Candidate selection: democratic centralism or managed democracy? In M. Gallagher \& M. Marsh (Eds.), How Ireland Voted 2007: The Full Story of Ireland's General Election (pp. 48-64). Palgrave Macmillan UK.

Witko, C., \& Friedman, S. (2008). Business Backgrounds and Congressional Behavior. Congress \& the Presidency, 35(1), 71-86.

\title{
Notes
}

\begin{abstract}
${ }^{1}$ The choice to limit the analysis only to incumbents was primarily a practical one. None of the seven measures of local roots I describe later in this paper are reliably available for challengers, and all are uniformly and reliably available for incumbents. Local roots may well be valuable to any candidate for U.S. House, but given the comparability between different incumbents' reelection goals, institutional positions, and type and size of campaigns, limiting this analysis only to incumbents was the prudent theoretical and methodological choice.

${ }^{2}$ And crucially, these local roots are formed entirely prior to their time in Congress, and are therefore exogenous to incumbents' electorally-motivated behavior once they are elected. Local roots only change for an $\mathrm{MC}$ if the geographic boundaries of their districts change.

3 From live "Congressional Exit Interview" event from the R Street Institute; 9/13/18

${ }^{4}$ MCs with family political roots that lie outside of their district were excluded from this designation.
\end{abstract}

${ }^{5}$ No MC over this period scores positively for all 7 component measures, making the scale 0-6 in practice.

${ }^{6}$ An additive index assumes that all 7 components are equally impactful for an MC. It is possible that some components matter more than others, and/or that their importance varies between MCs or district types. As a robustness check, I used factor analysis to produce an alternate Local Roots Index as a composite factor score for each MC. As shown in Figures A1.1 and A1.2 in the Appendix, the factor score produced similar results to the additive index. I use the latter in the main analysis for the purposes of simplicity and fidelity to the observed data.

${ }^{7}$ An additional robustness check (also in the Appendix, in Table A2.1) replaces the additive index with each individual component factor in turn; while some have higher impacts than others, most are positive and statistically significant by themselves. Including all 7 factors separately from each other in a single model would also be an incorrect approach, since doing so assumes that the effects of the 7 factors are all completely independent of each other, when in fact they all are indicators of a unifying concept.

8 These high-percentage incumbents were clear descriptive outliers in the data: that is, there is a small but significant clustering of incumbents from $95-100 \%$ of primary vote share, while the rest of the sample is fairly normally distributed around a median of $80 \%$. While these incumbents a technically challenged in that an opponent's name appeared on the ballot, there is no meaningful campaigning, and participation on the part of voters and candidates is therefore minimal. These incumbents can thus be said to be virtually unopposed. Only about $7.6 \%$ of incumbents from 2002-2018 fit the 95-100\% designation, and removing it does not substantially alter the results.

${ }^{9}$ These states include Washington (2008-present), California (2010-present), and Louisiana (2002-present).

${ }^{10}$ One notable omission from the in-text models for $\mathrm{H} 2$ is the quality of the primary challenger(s) facing off against the incumbents of interest. This control is omitted because there exists no easily attainable measure of challenger quality at the primary stage for the timespan of this study. However, Table A2.2 in the Appendix displays the raw results of an analysis identical to that of Table 2, but which also controls for total combined fundraising of all primary challengers as a proxy for quality. This is a problematic measure given the inherent endogeneity between 
campaign fundraising and outcomes; as such I do not include it in the main model in the text. Even so, the substantive and statistical significance of local roots decline only slightly in the alternate specification in Table 3.

${ }^{11}$ It is certainly true that MCs do not "randomly" attract challengers, which in theory could present an issue of selection effects for results of Hypothesis 2. Selection models using a Heckman correction for H2 (see online appendix) demonstrate robust results. However, I use regular mixed-effects modeling in the text because Heckman corrections do not generally allow for the use of mixed effects; and since the results for Hypothesis 1 account for these "missing" incumbents and have already shown robust results and identified this bias clearly.

${ }^{12}$ Rather than measuring the substantive impact of the independent variables for minimum and maximum values of continuous independent variables, Figure 5 reflects the more conservative effects of moving from the 20th to the 80th percentile of observed values of these variables (except for binary variables such as the jungle or closed primary conditions, for which predictions at 0 and 1 were generated).

${ }^{13}$ These results can be found in Tables A2.4 and A2.5 in the online Appendix. 